\title{
Computing and the Current Crisis: The Significant Role of New Information Technologies in Our Socio-economic Meltdown
}

\author{
David Hakken
}

Professor of Social Informatics

School of Informatics and Computing

Indiana University

Bloomington, IN

dhakken@indiana.edu

Contribution to the tripleC-special issue "Capitalist Crisis, Communication \& Culture", edited by Christian Fuchs, Matthias Schafranek, David Hakken, Marcus Breen

\begin{abstract}
There is good reason to be concerned about the long-term implications of the current crisis for the reproduction of contemporary social formations. Thus there is an urgent need to understand it character, especially its distinctive features. This article identifies profound ambiguities in valuing assets as new and key economic features of this crisis, ambiguities traceable to the dominant, "computationalist" computing used to develop new financial instruments. After some preliminaries, the article identifies four specific ways in which computerization of finance is generative of crisis. It then demonstrates how computationalist computing is linked to other efforts to extend commodification based on the ideology of so-called "intellectual property" (IP). Several other accounts for the crisis are considered and then demonstrated to have less explanatory value. After considering how some commons-oriented (e.g., Free/Libre and/or Opening Source Software development projects) forms of computing also undermine the IP project, the article concludes with a brief discussion of what research on Socially Robust and Enduring Computing might contribute to fostering alternative, non-crisis generative ways to compute.
\end{abstract}

Keywords: Crisis, Computing, Intellectual Property, Commodification

Acknowledgement: The author wishes to acknowledge the sabbatical support of Indiana University and the intellectual support of his colleagues at the University of Trento, Vincenzo D'Andrea and Maurizio Teli in completing this article.

\section{Introduction: Why the Current Crisis Needs to Be Understood}

Like other of the crises that periodically afflict capitalist political economies, the international meltdown that began in $2007^{1}$ has occasioned considerable discussion. Generally, American social

\footnotetext{
${ }^{1}$ Dating is often an important part of identifying important events in social formation reproduction, of which this crisis is surely an example. I believe one should strive to make strong connections among dates and names chosen and how one conceptualizes the character of the event (e.g., the crisis)—it's basic outlines and "nature." Dating and naming also have implications for what comes to be seen as needing to be done about the crisis-how to end it or at least mitigate its consequences.

I date the crisis from late summer to early fall 2007 , basically at the point when problems in the US housing and financial markets led to a radical tightening of access to credit, a tightening that quickly spread to other national social formations. That these US developments quickly led to a general crisis was substantially enabled by the immediately preceding forms of the "financialization" of the "developed" economies; e.g., that "ownership" of a substantial proportion of assets had been transformed into (or at least closely linked to) "innovative financial products" like collateralized debt obligations and credit default swaps. (The Financial Times estimated that by $200780 \%$ of the US economy had been so financialized.) In short, events in late 2007 reached the crisis stage, when the transformation of the character of asset ownership amplified the substantial negative developments in one region as it transferred them to wide swathes of commodity production activity around the world.

Nonetheless, from a non-American point of view, a case could be made that the crisis really only began in 2008, with a radical tightening of credit in Europe and the movement of financial problems from peripheral, smallish institutions to the big trans-national actors. Thus, I am aware of the Americano-centric tilt implied by my so dating/naming the crisis. Why I think such a tilt is justified will become clear, I hope, through my emphasis on the role of the US as the center of both the financial
} 
commentary about the crisis has manifest the "crackpot realist" pragmatism that C. Wright Mills identified as characteristic of US social discourse (1958); that is, the presumption that crisis talk should focus mostly on what "must be done right now" rather than on causes. Indeed, at the time I began writing (late fall, 2009), the crisis was still generally talked about episodically; that is, as if it were like a sporting event or movie plot. At the initial panic has receded, even less attention has been given by the business press to the crisis' residues and how to account for them, how it is different from its predecessors, and any new mechanisms needed to end it and/or avoid this kind of crisis in the future.

Arguably, the crisis continues today. While some signs are interpreted as indicating that is "bottoming out," others are said to support the view that it is continuing, perhaps in the form of a "double dip" recession. In any case, the length and virulence of this late "naughties" (2001-2010 decade) crisis have compelled some scholars and social commenters to insist on asking "why?" Despite the popular view (including that of the Queen of England) that "nobody saw it coming," several authors (e.g., Foster and Magdoff, 2009; Galbraith, 2008; Krugman, 2008; Kuttner, 2007; Marglin, 2008; Schiller, 2008) did, and they have provided insightful economic analyses. They all make the case that this crisis has unique features and residues that will have to be addressed if this kind of crisis is to be really ended and never repeated.

It may be that the changes associated with the crisis will be endured without its uniquenesses being widely understood. It is indeed likely that a particular account will only be acknowledged to be authoritative at some point in the distant future. Nonetheless, the longer its causes remain unclear, the less guidance we have for dealing with its residues, let alone preventing its next manifestations (if any). Hence, we should be sifting through what we know about the crisis to identify the actors and actions most responsible for it and the changes in social formation reproduction with which it is associated.

In this article, I wish to build on the economic analyses and frame crisis analysis in terms of the way contemporary social formations are being reproduced (Hakken 1987). ${ }^{2}$. Doing so makes it possible for me to identify one particular feature that is distinctive of this crisis. Before going further, I need to explain two presumptions on which my analysis is based. One is that, as the perceptive reader will have noticed, I refer to the crisis in a somewhat generic, less marked manner, rather than as a specifically economic one. (This is why I use "socio-economic meltdown" in my title: to connect enough to common usage that the reader will have some idea of my topic but also to indicate that my analysis is not limited to narrowly economic perspectives). Despite its obviously important economic dimensions, it is not only an economic crisis as these are commonly conceived; i.e., it is not a problem limited to a discrete aspect of the social formation that can be called "the economic." To presume terminologically that the crisis is only an economic one would limit enquiry into its possible features and sources.

As a somewhat more general crisis, its analysis is open to other scholars. This includes scholars like me, trained in and for having many years practiced the discipline of socio-cultural anthropology.

and the computational innovation on which I focus analytically, to say nothing of the pre-eminence of the US military in policing world political economy.

Finally, while choosing a date, I refrain from choosing a name for the crisis, using synonyms like "meltdown" rather than modifying adjectives that imply a kind, as I would were I to call it a "financial," "economic," or even a "global" crisis. While all of these may be accurate, I refrain basically because I think we still don't know what kind of crisis this is - that is to say, which social institutions are implicated, how much they will have to change, and where.

${ }^{2}$ As the use of the phrase "social formation reproduction" connotes, this essay is located within an intellectual terrain that concentrates on the ways in which human social and cultural relations are perpetuated. Stated briefly social formation reproductionist theory begins with a contrast between the ways individual life forms and broader human social arrangements perpetuate themselves. While the former follow a course largely dictated by the way in which genetic potentials interact with particular material conditions and leading to a rather substantial momentum, the latter are only perpetuated through deliberate collective actions, from mothers teaching daughters to formal school systems. Put simply, social formation reproduction is much more contingent than physical reproduction. Thus, if one is interested in a change (e.g., the emergence of a crisis), it makes sense to concentrate upon changes in either the forms through or the conditions under which such deliberate reproductive effort takes place (e.g., the switch from professional judgment to computationalist, algorithmic models of risk assessment) (see Hakken, 1987). 
We, too, can contribute to understanding why it happened/is still happening ${ }^{3}$. If this is a more general crisis in social formation reproduction, my views might also have credence. Financial Times Business Section Editor Gillian Tett, one of the earliest writers to grasp the breath-taking scope of the crisis (e.g., 2007), attributes her ability to do so to her PhD education in and continued practice of the holistic, integrative anthropological perspective.

Moreover, no less an expert than Alan Greenspan has remarked on the way in which the ideological presumptions dominant in mainstream economics (doctrines like the "efficient market" thesis) blinded economists, including himself, to the developing crisis (e.g., Financial Times, 2009). Their blindness means he and his kind are therefore not in a good position to claim exclusive right to describe it, let alone to be the only ones qualified to provide satisfactory accounts of it. As it is hard to imagine a performance worse than that of mainstream economists in predicting this crisis, it makes sense to listen to what other scholars have to say.

\section{Computing and Crisis}

In my view, what is distinctive about the current crisis is new and significant ambiguities in valuation, the process by which particular cultural forms are assigned particular values, including but not only their values as commodities. Further, I think one kind of social practice - the way automated information and/or communication technologies have normally been used, or "computing" for short-is central to the creation of these ambiguities, that computing has played a key, insufficiently understood role in bringing them about. Thus, focusing on how we compute, and more generally, the role of technology in the crisis, provides a way to think more inclusively about it. Doing so broadens our focus, so we can attend to general changes in the dynamics of current social formation reproduction.

Thus, the articles' central contentions are:

- That the co-occurrence of the crisis and a substantial increase in the degree to which human activity is computerized is indicative of a substantial (e.g., what used to be called a "causal" (Campbell, 2005)) connection between them;

- That the substantial connection between crisis and computing is likely rooted in financial entities computerized in the dominant "computationalist" manner, which in turn are the primary source of the ambiguities in valuation that give the current crisis its special character;

- That this unique feature of the current crisis is one facet of a more general intervention, several efforts to commodify a greater proportion of the reproductive dynamics of contemporary social formations (including the "invention" of "Intellectual Property" (IP)) rather than other facets of computing (e.g., web 2.0 or "playbor") or of social formation reproduction (e.g., globalization) currently given much attention; and

- That the contemporaneous, widespread development of alternative ways to compute, such as Free/Libre and/or Open Source Software (FLOSS), exacerbate the current crisis while also modeling forms of computing which, being less generative of crisis, are worthy of additional study.

I argue that calling it a "computing-induced crisis" is justifiable in the registers used by contemporary social theorists to talk about social causation, ${ }^{4}$ that understanding how we currently com-

\footnotetext{
${ }^{3}$ The focus of my field research over the last thirty years has been the social correlates of the use of automated information and communication technologies. In earlier periods, I carried out comparative field research on computerization in small regions in the US and the UK, on the role of national policy on these correlates in Scandinavia, and Free/Libre and Open Source computing in Malaysia. Most recently, I have concentrated on the connections between dominant forms of computing and the crisis, primarily by regularly monitoring the business press, especially the Financial Times, and by teaching and trying with colleagues to develop a social informatics research agenda within the new School of Informatics and Computing at Indiana University.

${ }^{4}$ With the exception of a large portion of economics and psychology, most social scientists no longer talk about causation in the deterministic fashion characteristic of laboratory- (but not field-) based natural science. While some students of human activity attempt to avoid any attempt at explanation (e.g., Clifford Geertz's famous comparison of ethnography to literary
} 
pute is necessary in order to specifying the alternative computing practices needed to avoid similar crises in the future. The dynamics of social formation reproduction have changed, computing has much to do with the change, and the change is manifest in but not caused by new relationships among workers, managers, and consumers at the point of production. Rather, the new dynamic of crisis follows from implementation of a new way of conceptualizing the role of computing in the creation and sale of a range of new financial commodities. This new ideology of using computers to extend commodification fit with certain additional changes in, e.g., legal instrumentalities like "intellectual property." While intended to aid the reproduction of capital, the new moves have (thus far) caused more problems that they have solved-i.e., have produced crisis.

Making this complex case definitively would require more than a single article. Here, I sketch out my argument, beginning with the reasons for seeing a connection between crisis and the dominant forms of computing as it was breaking. I then outline some alternative, non-computing-oriented accounts of the crisis and why I don't find them as persuasive as a focus on computing. Next, I draw out the connection between computing's dominant forms and attempts at a new property regime, showing how the failures of these forms and this regime are intimately connected to the crisis. I then explicate the paradoxical role of FLOSS, in both exposing flaws in the regime and furthering crisis. I conclude by discussing how to identify the different, more socially robust ways to compute that are required if we are not to experience this kind of crisis, or even more virulent varieties of it, repeatedly.

\section{The Ways in which Computing Bears Responsibility for the Current Crisis}

Stated positively and in broad-brush terms, I see four ways in which computing, especially a particular form of it that I call "computationalist" has played a central, generative role in the current crisis. I see these four forms as being sufficiently prior to the crisis in both logical and temporal senses to speak of them in a loose but still meaningful register (see footnote \#3) as causative of the crisis. They are:

1. Perhaps the most obvious crisis-generative aspect of computing is the profoundly instrumental role it played in the creation and marketing of a broad range of new financial instruments; that is, in new forms of financialization. "Financialization" of an economy occurs when a substantial proportion of capital realization takes place through the creation and sale of abstract monetary instruments, rather than through the production and sale of "real" (material) goods and services. Following Baran and Sweezy (1966), Foster and Magdoff (2009) make a convincing case that financialization has long been the chief strategy of late capitalism for fighting against the tendencies toward stagnation. Financialization has been evident in many capitalist economies since the 1970s; thus, the current crisis cannot follow from financialization in general. However, crisis does follow from the spread of particular, highly computer mediated financial instruments upon which the realization of profit became very dependent just prior to the outbreak of the current crisis. Instruments typical of the current form of financialization include those that garnered most public attention, the sub-prime mortgage-based securities created largely in the United States and marketed worldwide. Equally important to the crisis, I believe, were other computered commodities, including those collateralized in new forms of debt obligation (engineered by mixing several financial components into complex and largely opaque new entities, and similarly sold via new (international; see below) markets in securities), and parallel, equally nontransparent credit default swaps (essentially a financialized form of insurance).

2. Computing is heavily implicated in the emergence and trade of all these new commodities. Given their complexity, none of them, nor markets in them, could have existed without it. Nor

criticism (2000)), the majority still see the aim of social science as accounting for social processes (e.g., Campbell, 2005). Typically, this means identifying correlations among social phenomena (e.g., the current crisis and particular computing practices) that justify at least a preliminary presumption that the presence of one is connected is some structural manner to the presence of the other. Giving up on the aim of establishing absolute truth between essences, these social scientists aim for accounts persuasive enough to, for example, provide heuristics for social policy. 
was computing's role merely one of creating the possibility of doing such things. Only a few of the forms of financialization that were possible to computerize were actually developed (Tett 2009b). Those financial commodities that were developed and marketed were given the properties they had via what computer people call "affordances"-inclinations that, given existing preexisting developments or "path dependencies," are likely to follow, unless action is taken to prevent them. Indeed, many of the AICTs that made these new commodities possible were developed precisely in order to create things like them. This path dependency was a consequence of the particular mix of the entrepreneurial and technical built into contemporary education in and the practice of computing. In short, to the extent that computing was essential to these commodities' creation, and that market failures in these new financial commodities were central to the crisis, computing caused the crisis.

These computered financial instruments strongly afforded the elaboration of national markets for capital into a virtually global single market. Just as a desire for new commodities to trade in, so that more money could be made, drove computing development and implementation, so the development of international computing networks strongly incentivized creation of an unboundried market in capital. Indeed, the two go together; prospects for profitable trading in the new financial instruments were directly related to the extent to which the reach of the capital market could be scaled up.

However, this up-scaled market was formed without a simultaneously up-scaling of a parallel set of governance tools with which to regulate the trade carried out on it. The importance of such social arrangements to the orderly realization of more value, especially when the extra value was to be realized in new forms, was pointed out long ago by, among others, Adam Smith. The problems of weak governance of capital markets were exacerbated by the fact that these financial commodities were less subjected to the discipline of the physical world of material objects and life forms, as is more the case in what economists refer to (delightfully!) as the real economy. A consequence of the implementation of a computing-enabled near universal but institutionally underdeveloped capital market was increased volatility that contributed significantly to the crisis.

3. Less publicized but equally central to the generation of crisis were the widely adopted, computered models of the risks to sellers and buyers associated with trade in the new financial instruments. As the instruments were new, there was no "track record" of actuarial data on which to base judgments regarding the risks involved in buying, holding, and selling them. One consequence was major difficulties in pricing them, the implications of which exacerbated by the absence of forms of international governance in up-scaled markets.

Indeed, were it not for the development of complex, algorithm-based (computerized) risk assessment tools, trade in the new commodities, especially international, might well have remained marginal to capital realization. Moreover, the tools that were developed were based on presumptions like the idea that sufficiently detailed models would capture all relevant risk factors, as well as the notion that risk would follow the normal statistical distribution. As Gillian Tett demonstrates (2009b), these computer-based risk models were applied far beyond the intended applications of their initial developers. Presumed to be reliable, they became essentially the basis of price-setting models in the new financial instruments.

The arrival of crisis demonstrated these risk models were faulty. Numerous scholars and commentators, following Nassim Nicholas Taleb (2007), critiqued the models' for their failure to incorporate the risk of the kind of general "systemic" failure that actually did occur. Since algorithmic models must presume systematicity, they are generally incapable of incorporating "black swan/long tail" risks, like that of general failure. While incorporation of such factors might be theoretically possible, the models themselves, presuming systematicity, cannot generate theoretically defensible estimations of the likelihood of systemic failure.

From a social informatics perspective, it is obvious that the widely used computer-based risk models, relied on to such devastating effect, manifest particular ideological presumptions. The one of central concern to me is what Golumbia (2009) calls "computationalism." On the rational- 
ist presumptions of computationalism, anything modeled via computing is presumed to have systemic properties; otherwise, such modeling is impossible. In other words, computerizing risk models were in practice based on the presumption that the possibility of systemic failure could be effectively ignored. The use of such models contributed to the crisis by blinding financial actors to failure's possibility.

This is not to suggest that such models cannot be suggestive and helpful. The problem in the new financialization was the complete reliance on computered risk models, rather than their judicious use as tools to aid the competent professional. Their use was indicative of how the ideology of computationalism was a near-universal presumption of financial practice.

Another typical feature of computationalism is "informationalism." This is the presumption that all information about a phenomenon can and therefore should be included in its modeling, irrespective of the information's source, its verifiability, etc. On informationalism, the rule is, "The more information, the better." As computer models can now be expanded to include more or less any existing information, and because more information is presumed to be always better than less information, reason no longer exists to evaluate, and thus potentially ignore, any information. Notions like "the wisdom of crowds" (Suroweicki, 2004) are virtually pure statements of informationalism. In its naive presumption that, as more information is added to the model that is, the more computable it becomes - its accuracy tends to increase, informationalism becomes an aspect of computationalism. In short, reliance on prestigious, information filled, but systematicity presuming and therefore blind to systemic crisis, and thus deeply flawed, computationalist computing also caused the crisis. In this way, the models contained too much information, on the one hand, while ignoring crucial information (i.e., regarding systemic risk) on the other, because it was not easily quantified.

4. Asset value unknowability as the core of the current crisis: this point will be dealt with in more detail in the next subsection.

\subsection{Asset Value Unknowability as the Core of the Current Crisis}

In at least three additional important ways, the computerization of financial instruments led to a situation where assets' values became ambiguous and increasingly unknowable.

- First, one way traders can ascribe a value to an asset (the way on which the Basel II accounting conventions initially insisted) is to "mark to market." This means to ascribe as the value of an asset the value it itself, or other assets similar to it, fetched when last traded. Marking to market makes sense and works well as long as markets are active. However, when in 2007 many markets (e.g., that in sub-prime mortgages) began to seize up, it was no longer possible to mark to market. As there were few if any "free market" sales of the "troubled" financial assets described above, and thus no market to mark to, one could only, in the words of one trader quoted by the $F T$ (and himself quoting Warren Buffett), "mark to myth"

- It is true that some of these difficult to value, "troubled" or "toxic" assets have nonetheless been sold. However, the buyer has often been some government or government controlled entity. These sales arguably had much to do with the state's desires to, e.g., save entities "too big to fail" or to concentrate toxic assets in a "bad bank." The prices of such assets, not ar-

${ }^{5}$ The "mark to market or mark to myth" problem persists, as evidenced by the decisions made surrounding the "stress tests" of bank assets carried out in Spring, 2009, by the Obama administration in the US. In the absence of "free" (i.e., nongovernmental) markets for troubled assets, one alternative might have been to rely on a panel of outside experts to assign their "best guess" evaluations. Instead, the Treasury Department used the values that the banks in question chose to assign to their own untradeable assets. Consequently, no bank was determined to have "failed" the stress test.

Arguments could and have been made that this decision was important to the task of rebuilding confidence on fragile institutions "too big to fail." I choose here not to contest this dubious claim in detail, only to point out the likelihood that such procedures, while perhaps having short-run benefits, do look much like "kicking the can" further down the road, where they may foster more virulent crises. 
rived at "freely" and anyway ascribed within national, not global, capital markets, are political and thus meaningful only within the (possibly narrow) ambit of the power of the state in question; their market value, as this is normally understood, remain ambiguous.

- There is a third element contributing to asset value ambiguity. Discovering prices is made additionally difficult because, while capital in the form of computerized information markets has become globally fungible, there are no global, only national, practices that certify value in even the weak (mark to myth or state dictated) ways outlined above. As Smith argued, a functioning market, including one in capital, requires an infrastructure of social institutions (laws, regulatory agencies, institutions to certify requisite skills, etc.) as well as locations, like a (market)place, for buyers to meet sellers. In the absence of such an infrastructure operating on a global scale, all that can be done (and in this sense the FTs wag is correct) is to make up a new stories or "myths" about value and to hope that enough people collude in their telling that arbitrary but agreed-upon-and-therefore-workable evaluations not only can be but do often stick. ${ }^{6}$

- Asset unknowability has numerous consequences. For example, In the US, even by the summer of 2010, the market in loans to small businesses was still barely functioning, one indication that the crisis continues. Even now in the second half of 2010, many financial institutions continue count the price of acquisition as the value of the asset at the time of its acquisition, despite knowing that there is no market for it at this price. This is one reason why first the US, and now Europe, engage(d) in the dramaturgy of "stress tests." For financial journalist Henry Spender "Enduring uncertainty over how to value complex securities - a problem at the heart of the global financial crisis - highlights the scale of Washington's challenge in reforming the sector..." (2010).

The size of the decline in value is doubtless huge; the International Monetary Fund estimated in March 2009 that the crisis had destroyed something like 50 trillion dollars in value. At one point, Tett estimated that many "troubled" assets would ultimately be redeemable for around $5 \%$ of their face value (2009a). In any case, the more general point I wish to make, following Tett, is that, despite their huge importance to current social formation reproduction, the accuracy of any such estimate is questionable. This is because current values are a) are unknowable because of the inability to mark them to market, b) have either been assigned value arbitrarily to meet some state objective, c) kept as the price of their acquisition, despite the absence of any potential buyers at this price or d) concocted and colluded in by a group of people for whom any price is better than no price.

In short, a unique, perhaps the unique, characteristics of the current crisis is precisely these huge, persisting socio-economic spaces of unknowability. Given that a huge proportion of economic activity (Tett estimates some $80 \%$ ) was financialized, this unknowability is lodged at the cen-

\footnotetext{
${ }^{6}$ Indeed, only two solutions to the dilemma of an effectively global marketplace but at best only national infrastructures for redeeming capital seem logically possible. One is to create a global redemption infrastructure, to move from demi- to real globalism in capital market support infrastructures. The second is to de-globalize and then re-nationalize capital markets, to go back as it were to the institutional pattern that existed between the First and Second World Wars.

The creation of global redemption infrastructures would require surrender of national sovereignty over a broad range of nationally treasured institutions. The lack of coordination thus far among nations regarding the proper policies for dealing with the crisis suggests that this option is highly unlikely to be pursued effectively. This conclusion is regularly reinforced by the difficulties of creating consensus on policy in the United Nations, NATO, or the European Union. Even those who believe that one can have global governance without global government, who are willing to try to solve such problems technocratically rather than democratically, can draw little confidence from the experience of entities like ICANN and WIPO.

Alternatively, several nations have maintained structures that place limits on international capital flow (e.g., the Chinese control over currency exchange rates and foreign direct investment). Still, there is no effort to re-establish strong, general national boundaries to the movement of capital among nations; even in China, the role of Taiwanese capital continues to be a critical element of economic development. I believe one cannot be any more sanguine about prospects for the reimposition of national markets in capital.

In short, the virulence of the crisis is likely to continue to wax and wane. A continuing the lack of fit between marketplace up scaling and infrastructural stagnation mean that the combination of computer-enabled financial engineering and the uneven up-scaling of the level of social formation reproduction is likely to tend to amplify crisis.
} 
ter of the reproduction of contemporary capitalist social formations. The consequences of the lack of fit between the particular forms of computer-mediation of financial assets, on the one hand, and the wide swathes of unknowability to which their use led, on the other, have been amplified by the substantial upping of the scale (e.g., the "globalization" of markets in capital) at which some aspects of social formations (but not all) are able to be reproduced, further increasing the difficulty of establishing what specific value any given asset has. Indeed, it seems to me that the crisis will continue as long as a substantial body of difficult to evaluate assets persists.

In sum, by 2008 , many large social formations were in crisis. This crisis was a function of an economy highly mediated by a particular form of financialization (Tett, 2009a) which itself was afforded by a particular form of computing. The absence of any of the four ways outlined above in which computationalist computing afforded shaky financialization would have reduced the salience of the other two; all four seem central to a specific computing regime, a computing sociotechnological system in the sense of Thomas Hughes (2004), or a computing technology actor network in the Science, Technology, and Society language of Callon and Latour (1992). In the absence of such a computing regime, there may have been a crisis, but it would likely have taken a different, possibly less virulent form. ${ }^{7}$ As such, it would have been more easily dealt with by previously understood, Keynesian means, rather than the extraordinary interventions of bank nationalizations and Troubled Asset Relief Programs (TARPs).

\section{The Crisis and "Intellectual Property"}

To this point, I have partially fulfilled the ethnographer's task, which is to knit together a description of several observed phenomena (e.g., extensive spread of new forms of computing and ambiguity-induced difficulties capital reproduction) in a way that "makes sense." Ethnographically, the more observables one can fit together into a coherent account, the greater the extent to which one accounts for, not just merely describes, how things are. To this point I have stressed that social formations in crisis and having computerized capital reproduction got themselves to a point where they could no longer valuate the form of capital - financial commodities - on which their reproduction had become centered. How did this situation arise? Are there developments in other aspects of social formation reproduction that broaden out the dynamics described above?

The answer to these questions lies in recognizing that the new financial commodities discussed above are only one part of a wider program to commodify large new swathes of social life, by turning diaphanous things like notions, ideas, and social relations into commodities. It is common, in capitalist social formations, to attempt to deal with crisis by extending the reach of commodification. For example, when two parties engage in mortgaging, the house is the prime commodity, the mortgage representing the social relation between the buyer and the lender. When this mortgage is turned into a collateralized debt obligation, the mortgage is being treated as a thing rather than as a social relationship.

Transformations similar to the commodification of the mortgage inhere in the set of cultural practices associated with the invention and promulgation of so-called "intellectual property" (IP). By "invention of IP" I mean the rather sudden and widespread reuse of IP as a cover term. Used briefly in the $19^{\text {th }}$ Century, this specific phrase reemerged in English speech in the mid-1980s, likely around attempts to patent software. I first encountered IP rhetoric in conjunction with a renewed push to computer higher education by getting university faculty to put their courses "on line." As

\footnotetext{
7 A good "creative destruction" case can be made, in the spirit of Joseph Schumpeter (1942), that the spread of computing had a substantial anti-stagnation effect. I certainly acknowledge that the size of the market in computing artifacts (hardware and software) and services themselves, the broad spread of computer-based practices into virtually every major form of human endeavor, even the widely-held belief that "computers change everything" certainly suggest this. I also acknowledge that a case could be made that, even with the crisis-generative aspects of computing that I have identified taken into account, computing may have been more beneficial for the reproduction of capital than detrimental. As I suggest in my conclusion, one can also argue that computing need not necessarily be used in the ways I have described, that alternative ways to compute might have been deployed that manifest neither computationalism nor informationalism. In short, my chosen task is to provide an account for what did happen, not all that might have happened.
} 
part of its attempt to get me to do this, The State University of New York, my employer at the time, argued that, by doing so, I could better protect my "Intellectual Property." That is, I would be the one, not the University, who "owned" the course content (the use of which, of course, the university would have for a specified time period). ${ }^{8}$

Because computered education had been the focus of my first field studies of computerization, and also because I had over the subsequent years tried out (and been disappointed by) each new form of computered education as it became available, I took note of this new initiative. I remember joking that, up until the university's entry into the provision of teaching on line, the successful teacher was the one who gave away the most knowledge, as indicated by things like student evaluations. Would teachers now be evaluated on their effectiveness at preserving the scarce resource of knowledge by treating it as property?!

So what was really new in mid-nineties ed tech, beyond "the web" and "blogging," was the talk, especially its articulation in terms of IP. Before, I had understood my professorial mandate to be to give away as much knowledge as I could. Suddenly, I was given a the opposite obligation, to "protect Intellectual Property." While the examples of the IP needing protection offered tended to be that of individual professors like me, it became clear that the more powerful force behind this push was to generate corporate income by selling platforms, modules, or entire degree programs; it had little to do with my research and teaching. Moreover, the accompanying structural adjustments (e.g., the creation of university IP offices and associated legal documents that I was now obliged to sign) indicated a different agenda, one protecting institutional rather than individual property/opportunities for generating income. Nobody bothered to explain why my fundamental occupational reason for being had suddenly reversed 180 degrees. As in the prior moments of ed tech enthusiasm, my colleagues and I could clearly see the threat posed by more proprietized information to our ability to teach and do research. Hence, I was not surprised when the aggressive ed tech program largely evaporated in the midst of the early "naughties bursting of the "dot.com" bubble.

This is not to say computers have no place in education. The dominant mode of their use has for a long time has been (and currently remains) that of one of many aids to teaching - as in the "composite" on-line and congregate teaching that most of my colleagues and I now practice. In contrast to our lived experience, the ed tech hyper-enthusiasm suggested another agenda, that of first convincing professors like me to reconceptualize our relationship to ideas as private property rather than common resource. Indeed, as one advocate of educational technology explained to me then, the goal was to deal with the big problem with the education sector. From an economic point of view, the problem was that most educational resources were spent on salaries. If teachers could be replaced by products, or at least employees replaced by contracted services, companies could make more money, and in this way capital reproduction could be extended.

Shortly after this period, the early forms of the new financial instruments were being developed. Indeed, the "(re)invention" of IP was, whether in the form of new financial instruments or "teacher proof" educational computing, indicative of a broad effort to develop new ways of commodifying ideas.

What do people mean when they talk of "intellectual property"? It presumably has something to do with ownership of ideas. I am of course aware of pre-existing practices like copyrighting, trade marking, and patenting, which also involve proprietizing ideas. Interestingly, these are practices for which discrete terms served quite well for a long time before the label and rhetoric of "IP" were reapplied to them in the 1990s. Hence, the main question about IP is really what those performing this re-conceptualization were trying to achieve by it (and then what this has to do with the crisis).

\footnotetext{
8 I had studied an earlier attempt to commodify education in the 1970s (Andrews \& Hakken, 1976), when the business members of the Association for Educational Communications and Technology were trying to develop "teacher proof" materials to be run on mainframe computers. Since then, I pretty regularly experimented with each new "ed tech" tool as they came along. I found none particularly useful. This was in part because the tended to distort fundamental principles of my field, but also because the changes in institutional reward structures that would mean it made sense to put the considerable energy required into mastery of kludgy tools were never implemented.
} 
As argued regularly in the long history of institutionalist economics, from Veblen (1899) via Schumpeter (1942) through Marglin (2008) and Harvey (2007), a frequent element in capitalists efforts to support the reproduction of capital is to extend the reach of commodification - that is, to provide new terrain for capital reproduction by proprietizing aspects of social reproduction that had heretofore not been or had been less mediated by market relationships. The push for IP is an example of such an effort. I think it significant that the effort to obtain patent rights over software, largely via litigation, was the most aggressive aspect of the new IP regime. The recent effective abandonment of the effort to enclose software in this stronger form of proprietization (rather than leaving it under the aegis of the softer form of copyright) is one of several indications that the IP strategy for commoditization has not, so far, worked out all that well.

The unvaluability of a large group of assets was identified above as being at the heart of the current crisis. I see this as one of several difficulties encountered in the effort to proprietize culturally important but very non-material things like ideas (ed tech) or notions (new financial commodities) as "intellectual assets." A "financial commodity" is mythic, a particularly strong form of commodity fetishism. Recognition of this condition provides a starting point for explaining a problem that continues to stymie governments around the world, despite all the talk about economic "green shoots." The problem of "unfreezing" seized up credit markets is one form of a much more general problem, being specific about just what kind of thing is being valued.

At base, the unknowability of the new financial commodities is a consequence of the at base oxymoronic character of Intellectual Property. IP is an oxymoron in that, in order for the intellectual merit of, say, an idea, to be acknowledged and then valued on some quantitative scale of relative merit, it must first be communicated. However valuable I might consider my own ideas, there can be no compelling reason for another to share my evaluation without her first understanding them. For her to do this, I can't keep them private; I have to say what they are. I can't even get away with just saying what they are "like." However, once communicated, it is difficult to control the understander's use of the idea. Thus, any effort to turn ideas into private property faces a fiendish difficulty: how to keep control over things, like ideas or notions, that by their nature must be shared if they are to be evaluated. This problem is exacerbated by digitalization: once created, digital representations of ideas and notions are reproducible at extremely low cost (think of the cost to the writer of an email).

The mid-1990s ed tech push was an effort at commodification, just as was the development of new forms of financialization around the same time. IP was an ideological reconceptualization appropriate to the commodification of both professorial work, on the one hand, and that of professional traders, on the other.

Indeed, the difficulty in commodifying education more thoroughly is indicative of a more general problem with the strategy of trying to commodify the world of ideas. In the crisis, this general difficulty has emerged again with regard to the notion that a collateralized debt obligation has any more value than my private professorial thinking. All IP-related notions are problematic. (I would further suggest that the bursting of the dot.com bubble is also connected to the doubtful viability of the IP project, whether in "dot.com," ed tech, or new financial commodity guises.) I see similar forms of ephemerality in notions like "human capital," "social capital," and the proliferation of similar concepts (e.g., "attention capital"). They share what Marx described as the essential feature of the notion of "capital" itself; that the phenomena pointed at by the terms are at base social relations, but the terms being pushed for conceiving of them are themselves attempts to get people to treat these as relations not among people but among things. The new financial instruments are like these, only more extreme examples of fetishized commodities. In all these cases, actual social relations are masked and thereby made harder to deal with.

\section{Can Computing Solve the Crisis it Brought about?}

The current crisis should be seen as a consequence of particular attempts to use computing to promote the reproduction of capital by extending the property relationship further into the financial 
arena. Above I argued that a key conceptual basis of the standard, formal approach to computing computationalism - was the ideologically source of why this attempt led to crisis. Computationalists generate a great deal of data, then they use algorithms to manipulate these data in order to create ever more complex models, in the belief that such models generally provide more and better knowledge. Computationalism only makes sense as a basis for cogitation if the world itself is, for all-important intents and purposes, systematic; that is, its characteristics regular and perceivable. Computationalist computing, like the dominant forms of educational technology, is a particularly important example of an attempt to change social formation reproduction - proprietization of the ideational-that exacerbates the contradictions of capital reproduction. It follows that more computing based on computationalism will not be very helpful in resolving the current crisis, or be useful to the building of new accounts of the world, ones that do not presume the value of proprietizing the ideational.

Instead, resolution requires different approaches to computing. Fortunately, a search for approaches different from the rationalistic assumptions of neo-classical economics, the need for which is manifest in Greenspan's auto-critique, has already begun in economics. Much of this critique is emerging under the banner of "behavioral economics," although in my view alternatives are more directly expressed in the literature that foresaw the crisis (e.g., Kuttner, 2007; Galbraith, 2008; Schiller, 2008; Marglin, 2008). It is not more data, nor more manipulations of data, that are (were) needed, but new evaluative standards (or more precisely, new, agreed upon procedures for standard-making).

Different evaluative practices already exist within computing. Those associated with the Internet Society, the World Wide Web Consortium, and the Internet Engineering Task Force suggest the value of communalist, as opposed to individual proprietary, framings of computing. Even more important, I would argue, are the innovative social arrangements characteristic of many (but not necessarily all) Free/Libre and/or Open Source Software (FLOSS) projects. FLOSSing is particularly important because it demonstrated the viability of a very different approach to IP, as well as a different conception of the role of computing in social formation reproduction. Moreover, this viability was being demonstrated just as the crisis due to computationalist computing was leading to crisis, right at the time when the dominant IP strategy was being pursued most vigorously. Indeed, the success of FLOSS at producing viable code is arguably the most direct refutation of the notion that capitalist proprietization is key to the future of code.

Also of importance are the practices that have been developed in a number of Participatory Design exercises and other user-oriented activities carried out under rubrics like "web 2.0," some social networking sites and in the creation of things like Wikipedia. These practices are not only different. In one sense, by demonstrating the viability of non-computationalist computing, they can even be said to contribute somewhat to the crisis.

\section{Alternative Accounts of the Crisis and Why I Reject Them}

There are factors other than computing onto which responsibility for the current crisis might be put, other ways to explain the recent changes in the dynamics of social formation reproduction. Here I briefly identify some and then explain why I think computing is more responsible:

1. That this crisis is just a somewhat more virulent instance of the recessions that are acknowledged by the dominant neo-classical cum Keynesian economics (albeit sotto voce) to be a regular, recurring part of the normal business cycle. On such accounts, crises have similar characteristics at their core. Each crisis may have surface features particular to it, but these are not of great explanatory importance.

In response, I evoke another Greenspan view, that this crisis is indeed extraordinary, one inexplicable in terms of regnant economic theory. Indeed, this "nothing special" view is particularly unpersuasive, given the prior, near-universal hyping by mainstream economists of the idea that a "new economy" had arisen in the 1990s, a period they referred to as the "Great Moderation." 
This economy was held to be "new" in precisely the sense that it was claimed to have transcended the cycle of periodic recessions characteristic of the "old" economy, that crises would no longer be recurrent features of capitalist economies.

2. That "globalization," as described by, e.g., Tom Friedman (2004), the key change dynamic in recent social formation reproduction (SFR), is thus the cause of the crisis. The up scaling in information creation and communication to which Friedmanites attend were indeed greatly afford by the significant rise in, even arguably driven by, computing, as Friedman himself acknowledges. Further, this up scaling has amplified many of the more virulent manifestations of the crisis; e.g., it is why banks in Ireland and Germany could be both responsible for and destroyed by the bankruptcy of school boards in Wisconsin, USA.

I argue that, while rises in the scale of particular moments in social formation reproduction, including those glossed as globalization, are indeed implicated in the crisis, they are implicated more as mediators or contexts than as prime movers. Indeed, the crisis has obviated large portions of the globalizationist strategy for which Friedman was such an effective shill. Despite the stirring rhetoric of Group of 20 communiqués, actions to cope with the crisis have taken more national than global form. The crisis has revealed just how vulnerable and optional the allegedly inevitable force of globalization is. It makes much more sense to see the talk about globalization as a politico-ideological program, as "globalizationism," rather than as an emergent empirical characteristic "natural" to and exercising control over current social formation reproduction;

3. That recent changes in SFR dynamics are best explained by drawing attention to the policy of neo-liberalism or the "Washington consensus." Such an account overlaps greatly with the globalization perspective. Indeed, neo-liberalism depends upon an inevitabalist account of globalization in a manner similar to the way globalization depends on stories of computing as a force with ineluctable properties.

Both neo-liberalism and globalization are best seen as policy initiatives dressed up in empirical drag-i.e., held to be "inevitable" developments driven by, in Friedman's bold admission, the irresistible implications of computing; he is proud of being a technological determinist. If "the world [had already been made] flat" by computing, there would be little point in trying to control economic and social dynamics at the level of the nation, let alone the region or town. Yet is exactly the national level at which (often contradictory) efforts to meliorate this and avoid the next crisis are being carried out. Meanwhile, for some, the "decoupling" of Asian dynamic economies from enfeebled North Atlantic ones is held to "explain" why the crisis is ending! The Asian economies that have avoided crisis are those least influenced by neo-liberalism. In contrast, I argue that computing failed to have the "inevitable" consequence of a universal neo-liberal order precisely because of computationalism. This can explain why the world today is hillier than in Friedman's (or Bhagwati's, 2004) vision. The neo-liberal consensus, like globalizationism, is in at least rhetorical retreat. During the height of the crisis, even the Financial Times was asking, for a while, "Can capitalism survive?" (2009). While neo-liberalism and globalizationism can be distinguished from each other, they are also closely connected - neoliberalism is a program to minimize the influence over the reproduction of any social formation of any power other than that manifest in markets, while globalizationism would minimize the influence of any particular geo-political entity (e.g., nation or state) on the functioning of markets. Neo-liberalism and globalizationism can and often are often invoked together as a single unit, suggesting their close symbiosis beyond the ideological. For example, increased corporate power enables broader international reach, while broader geographic reach enables increased corporate power. Additionally, both massive neo-liberal increases in the influence of already powerful economic actors (e.g., corporations) and substantial increases of scale in several (but by no means all or even most) contemporary aspects of social formation reproduction both enabled and mediated the computing practices described above. 
Further, the combination of policy-led changes in power and scale also meant that the implications of adopting the forms of computing listed above were greatly amplified. Consider first the uneven up scaling, called "globalization" but better described as "demi-globalization." This latter characterizes a situation in which, while some practices have greatly up-scaled (e.g., the switch from largely national to an essentially global trading of/in capital), several others haven't (e.g., regulation, or enforceable procedures for converting commodities back into investable resources, or capital). It was the concurrence of the forms of computing described above with a demi-globalism justified by neo-liberalism that led Tett 2007) early to perceive the inability to value as distinctive of this crisis.

Thus, the ideological programs of globalizationism and neo-liberalism were important contexts for the crisis. However, as pointed out above, computerization was essential to both globalizationist and neo-liberal programs. In different but complementary ways, both contributed to the emergence of a large class of financial entities purported to be, and thus treated as, assets but whose current values were unknown that interfered directly with the reproduction of capital in numerous social formations;

4. That the crisis follows from a specific characteristic of all "human nature," in Greenspan's rhetoric, that of "greediness".

However, the performances of greediness were not equally distributed among all people but were instead highly concentrated, especially among those trading the new financial commodities. As sub-prime mortgages, collateralized debt obligations, etc., came about through (indeed, were enable to exist by) computing, the disastrous consequences follow from the affordances they gave to social formation reproduction, from particular practices of some individuals practice, not from a general human characteristic;

5. That a recent change in workers' role in the labor process, e.g., from labor to "playbor," causes crisis. Initially preceding but greatly expanding during the crisis, there emerged a new computing-related critical scholarship, manifest especially in the humanities, oriented to this idea. The argument centered on a trope familiar to those who have studied the on-going computing/social change connection empirically. The trope is that of interconnected, computing-induced change in work regime, value production, economics, and political structures. For example, the idea that computing has transformed work is the argument of Wikinomics (Tapscott \& Williams, 2004). What knits this talk together is that the changes are held to be caused by the widespread use of new automated (that is, computerized) information and communications technologies (AICTs). The term most widely used recently (but by no means universally) for the current, changeinducing forms of computing is "web 2.0." Among terms put forward to characterize the new form of work stimulated by web 2.0 is "playbor," (an elision of "play" and "labor"; see anon., 2009). On playbor, the boundary between work and play has been breached. For example when one posts content on YouTube or Facebook, one is engaging in a leisure pursuit that also gives free value to a corporation, thereby lessening the need for it to hire workers. One would expect those who highlight this change in the labor process would connect it to the most visible social dynamic, the crisis. One could argue, for example, that playbor displaces paid work, which raises unemployment, which in turn means fewer consumers with income to spend, which leads to crisis. Nonetheless, to the best of my knowledge, none of the "fundamental change at work" advocates has actually attributed the crisis to "playbor." Instead, they choose to focus on things like the implications of the new form of work for how worker exploitation has changed, or for political/social movement activity. In any case, the work processes in which playbor is arguably a central element remain marginal to work in general and therefore are not significant enough to explain the current crisis. 


\section{On the Professional/Ethical Responsibility of Computing Professionals}

The initial aim of my study was to understand what connection there was, if any, between the crisis and computer-induced changes in the labor process. Because the crisis and such changes co-occur in time, a search for ways is which they are structurally connected seemed likely to be rewarding. As suggested above, there are computed forms of work other than playbor (e.g., FLOSS development and Participatory Design) that have contributed to the crisis, but in an indirect way. That is, they are highly visible, clearly viable ways to compute different from the computationalist forms directly responsible for the crisis. In several ways, FLOSS and PD practices undermine the presumption that the only way to compute is to do so on computationalist presumptions. For example, many of its advocates claim that FLOSS leads to better software. Their argument is generally based on claims about the social dynamics of the development process; e.g., that code written by people who volunteer to make it is likely to be superior to code written on the instructions of a boss, or that having thousands of people looking for bugs is more likely to find them than are the members of a small proofing team. By undermining in an embodied way the ideological justifications for current forms of computing, these different forms at a minimum make it easier to see the connection between computationalist computing and the current crisis, thereby undermining its legitimacy.

It follows from my argument that those who compute professionally share considerable responsibility for the crisis. An ethical onus falls not only on those writing the code, implementing the systems and to implement them. It also falls on those who, like me, study what happens when computers are used (my conception of the core concern of the new to the US field of Informatics). This is because, to varying extents, our acts of study shape how we compute. It follows that, in addition to designing, implementing, and studying what happens when we implement, we have a professional responsibility to critique our designs, the use of the tools we make, and debate our analyses of what actually happens when people use them.

When we try to do so without surreptitiously importing computationalist presumptions, we can we draw upon the different traditions of FLOSS and PD to make different tools and choose different criteria of evaluation to get them used differently. Such alternatives will only lead to different computing if accompanied by an effective auto-critique of our past practices. Since we benefited from/are also responsible for creating the currently available contexts of use, we are obliged to participate in reshaping the (hopefully new) social context within which the new tools will be used. To change the context so that we can at least decrease the chances of having to go through another, and another, and...similar crisis, we have to find ways of encouraging other, less computationalist if equally computing-dependent, practices.

\section{Socially Robust and Enduring Computing}

New, more socially robust forms of computing - deriving from, inter alia, what I call the strong program ${ }^{9}$ in social computing - not only must but can be developed and should be implemented as part of a crisis recovery/avoidance strategy. Fortunately, some computer practitioners - whom I like to call informists - have some good ideas about how to pursue socially robust and therefore enduring computing (SREC; Hakken, 2010), ideas incubated within the non-dominant forms of computing that have refused to reduce themselves to formalisms alone. The alternative practices are central to the Social Informatics within which I frame my research and that I teach at the new School of

\footnotetext{
${ }^{9}$ The term "strong program" is a critical, descriptive advocacy notion widely used in science/policy circles. It is normally used to differentiate to an existing program, one that the critic believes has insufficient substance to reach its intended goals, from another, more extensive approach that would have enough substance. I am most familiar with the term's use by David Bloor in relation to efforts to develop a "strong" sociology of knowledge (SK); that is, explanations in terms of social process (rather than, say, inherent transcendent truth value) of why some perspectives are treated as "known" while others are not. Bloor was particularly sensitive to SKers avoidance of scientific knowledge, holding that a real or "strong" SK program would have to include a robust sociology of scientific knowledge (SSK). I explain below why I think the current program for social computing is in need of a similarly strong program.
} 
Informatics and Computing at Indiana University in the USA and at Trento University in Italy. Their ability to thrive, however, depends upon reinforcement of property regimes very different from IP and much more like the "commons" oriented regimes of FLOSS. Let us hope that commonsilluminative views, like those resulting in a Nobel Economics Prize for my Indiana University colleague Elinor Ostrom (e.g., 1990), come to provide a clear alternative orientation for professional computing.

\section{References}

Bourdieu, P. (1986). The (three) Forms of Capital. In J. G. Richardson (Ed.), Handbook of Theory and Research in the Sociology of Education (pp. 241-258). New York/London: Greenwood Press.

Giddens, A. (1984). The Constitution of Society. Berkeley/Los Angeles: University of California Press.

Mingers, J. (1996). A Comparison of Maturana's Autopoietic Social Theory and Giddens' Theory of Structuration. Systems Research, 13(4), 469-482.

Andrews, B. \& Hakken, D. (1976). Educational Technology: A Theoretical Approach. College English, 39(1), 68-108.

Anonymous. (2009) "Digital Playbor?" Caught in the Web 10/22/09. http://caughtintheweb.wordpress.com/2009/10/22/digital-playbor/

Baran, P. \& Sweezy, P. (1966). Monopoly Capital. New York: Monthly Review Press.

Bhagwati, J. (2004). In Defense of Globalization. Oxford: Oxford University Press.

Buffett, W. (2002). Berkshire Hathaway Annual Report. Omaha: Berkshire-Hathaway.

Callon, M. \& Latour, B. (1992). Don't Throw the Baby Out with the Bath School! A Reply to Collins and Yearley. In A. Pickering (Ed.) Science as Practice and Culture (pp. 343-368). Chicago: Chicago University Press.

Campbell, J. (2005). Where Do We Stand? Common Mechanisms in Organizations and Social Movements Research. In G. David, Gerald, D. McAdam, W.R. Scott \& M. Zald (Ed.) Social Movements and Organization Theory (pp. 41-68). Cambridge: Cambridge University Press.

Foster, J.B. \& Magdoff, F. (2009). The Great Financial Crisis. New York: Monthly Review Press.

Financial Times. (2009). The Future of Capitalism (special supplement, 5/12/09).

Friedman, T. (2004). The World is Flat. New York: Farrar, Straus, \& Giroux.

Galbraith, J. (2008). The Predator State. New York: The Free Press.

Geertz, C. (2000). Available Light. Princeton: Princeton University Press.

Golumbia, D. (2009). The Cultural Logic of Computation. Cambridge: Harvard University Press

Hakken, D. (1987) Reproduction and Culture in Complex Social Formations Dialectical Anthropology, 12(2), 193-204.

Hakken, D. (2010). The SREC Program (Social Robust and Enduring Computing): Achieving the Intercalation of the Social and the Technical in Computing. Presented at the iSchool Conference, University of Illinois.

Hakken, D., D'Andrea, V. \& Teli, M. (Forthcoming). Intercalating the Social and the Technical: A Key Step in Coordinating Future Software Development. IEEE Transactions on Software Development.

Harvey, D. (2007). The Limits to Capital. New York: Verso.

Hughes, T. (2004). Human-Built World. Chicago: University of Chicago Press.

Krugman, P. (2008). The Return of Depression Economics and the Crisis of 2008. New York: W.W. Norton.

Kuttner, R. (2007). The Squandering of America. New York: Vintage

Marglin, S. (2008). The Dismal Science: How Thinking Like an Economist Undermines Community. Cambridge: Harvard University Press.

Mills, C.W. (1958). The Causes of World War Three. New York: Simon and Schuster.

Ostrom, E. (1990).. Governing the Commons: The Evolution of Institutions for Collective Action. New York: Cambridge University Press.

Schumpeter, J. (1942). Capitalism, Socialism and Democracy. New York: Harper \& Row.

Shiller, R. (2008). The Subprime Solution. Princeton: Princeton University Press.

Spender, H. (2010). Short Measures. Financial Times July 19, p. 5.

Suroweicki, J. (2004). The Wisdom of Crowds. New York: Random House.

Taleb, N.N. (2007). The Black Swan: The Impact of the Highly Improbable. New York: Random House.

Tapscott, D. \& Williams, A. (2004). Wikinomics: How Mass Collaboration Changes Everything. London: Penguin.

Tett, G. (2007). Should Atlas Still Shrug? Financial Times January 15, p. 9

Tett, G. (2009a). Investors are Foundering in Post-Traumatic Syndrome. Financial Times July 24, p. 18.

Tett, G (2009b). Fool's Gold. New York: Free Press.

Veblen, T. (1994) [1899]. The theory of the leisure class. New York: Penguin Books. 


\section{About the Author}

David Hakken is an anthropologist whose ethnography of information aims to understand the ways automated information/communication technologies and social reproduction mutually shape each other. His research has been grounded in England, Scandinavia, Upstate New York, Malaysia and China. His most current work is on Open Computing (especially Free/Libre and/or Open Source Software) and Socially Robust and Enduring Computing. After twenty-six years in the State University of New York, he in 2004 began teaching social informatics in the new School of Informatics at Indiana University, promoting technologies that expand rather than undermine human capabilities. His book, The Knowledge Landscapes of Cyberspace, was published in 2003. 